\title{
Interferon-Lambda: A Potent Regulator of Intestinal Viral Infections
}

\author{
Sanghyun Lee ${ }^{1}$ and Megan T. Baldridge ${ }^{2 *}$ \\ 'Department of Pathology and Immunology, Washington University School of Medicine, St. Louis, MO, United States, \\ ${ }^{2}$ Department of Medicine, Division of Infectious Diseases, Washington University School of Medicine, St. Louis, MO, \\ United States
}

OPEN ACCESS

Edited by: Ivan Zanoni,

Harvard Medical School, United States

Reviewed by: Yunhao Tan,

Harvard Medical School, United States

Nicola Tamassia,

University of Verona, Italy

${ }^{*}$ Correspondence: Megan T. Baldridge mbaldridge@wustl.edu

Specialty section: This article was submitted to Molecular Innate Immunity, a section of the journal Frontiers in Immunology

Received: 05 May 2017 Accepted: 13 June 2017 Published: 30 June 2017

Citation:

Lee $S$ and Baldridge MT (2017) Interferon-Lambda: A Potent Regulator of Intestinal Viral Infections.

Front. Immunol. 8:749. doi: 10.3389/fimmu.2017.00749
Interferon-lambda (IFN- $\lambda$ ) is a recently described cytokine found to be of critical importance in innate immune regulation of intestinal viruses. Endogenous IFN- $\lambda$ has potent antiviral effects and has been shown to control multiple intestinal viruses and may represent a factor that contributes to human variability in response to infection. Importantly, recombinant IFN- $\lambda$ has therapeutic potential against enteric viral infections, many of which lack other effective treatments. In this mini-review, we describe recent advances regarding IFN- $\lambda$-mediated regulation of enteric viruses with important clinical relevance including rotavirus, reovirus, and norovirus. We also briefly discuss IFN- $\lambda$ interactions with other cytokines important in the intestine, and how IFN- $\lambda$ may play a role in regulation of intestinal viruses by the commensal microbiome. Finally, we indicate currently outstanding questions regarding IFN- $\lambda$ control of enteric infections that remain to be explored to enhance our understanding of this important immune molecule.

Keywords: interferon-lambda, enteric virus, innate immunity, transkingdom interactions, norovirus, rotavirus, commensal bacteria

\section{AN INTRODUCTION TO INTERFERON-LAMBDA (IFN- $\lambda$ ) IN THE INTESTINE}

Animals can mount potent and rapid innate immune responses to invading viruses. The classic signaling pathway by which this response occurs is via type I interferons (IFNs), including IFNbeta (IFN- $\beta$ ) and multiple IFN-alphas (IFN- $\alpha$ ) (1). When cells sense viral products, type I IFNs are produced, which stimulate transcription of antiviral molecules that act in autocrine and paracrine fashion. However, in the past decade, an important paradigm shift has occurred in how we consider the compartmentalization of viral responses into systemic versus mucosal responders, driven in large part by the discovery of type III IFNs, or IFN- $\lambda$.

First described in $2003(2,3)$, the IFN- $\lambda$ family of cytokines includes up to four members in humans, dependent on genetic polymorphisms $(4,5)$, and two functional orthologs in mice $(6,7)$. The family, likely arising from a common ancestral fish IFN gene that gave rise to both type I and III IFN families, is conserved to chickens $(8,9)$. The type III IFNs are under positive selection, with long-term persistence of duplicate copies suggesting a critical biological role for type III IFNs independent from type I IFNs (9). Pattern-recognition receptors, including RIG-I and MDA5, detect viruses and induce type I and III IFNs via MAVS and IRF3/IRF7 signaling (10-12) (Figure 1). IRF1 plays a unique role in type III IFN induction, however, being specifically stimulated by peroxisomeassociated MAVS in contrast to mitochondrial-associated MAVS, which better induces type I IFNs 


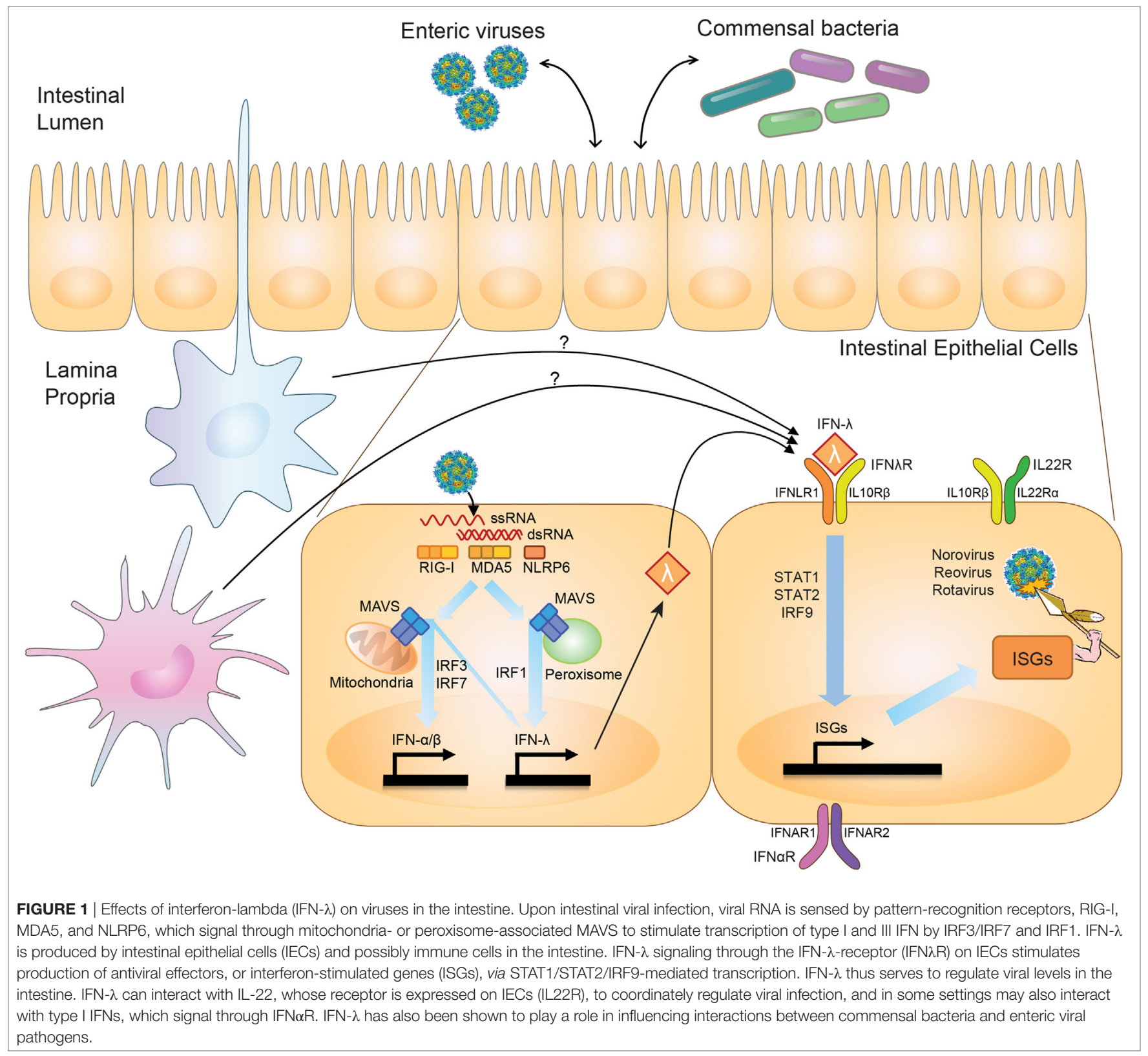

(13). Intestinal epithelial cells (IECs) produce type III IFNs with in vivo viral infection (14-16). However, leukocytes generate IFN- $\lambda$ in vitro $(10,17)$, and intestinal eosinophils (18) and plasmacytoid dendritic cells (pDCs) (19) can produce IFN- $\lambda$ in vivo, suggesting the possibility of additional cellular IFN- $\lambda$ contributors.

While the antiviral programs induced by type I and type III IFNs exhibit substantial overlap (20-22) (Figure 1), a critical difference between the two is the cell types they affect secondary to receptor expression. The IFN- $\lambda$ receptor consists of IFNLR1 and IL10R $\beta$. While the receptor for type I IFNs, IFNAR1, is expressed broadly on the majority of cell types, IFNLR1 exhibits a much more restricted pattern of expression (23). In the intestine, IFNLR1 is expressed preferentially on IECs, allowing for a compartmentalized response to viruses infecting at this mucosal surface $(24,25)$. While IFNLR1 expression has also been reported on NK cells, T cells, B cells, and pDCs (26-30), no role has been found for these cells in IFN- $\lambda$-mediated antiviral responses. Type I IFNs, on the other hand, are critical for preventing a virus from moving past this initial epithelial barrier into systemic tissues $(24,25,31)$. The host may benefit by inducing specific and local barrier defenses at a site commonly exposed to pathogens via IFN- $\lambda$ signaling, and thus avoid potentially detrimental systemic inflammatory responses by type I IFNs. Many autoimmune diseases, as well as the congenital interferonopathies, are secondary to excessive type I IFN activity $(32,33)$.

There is an ever-expanding set of roles being discovered for IFN- $\lambda$ signaling, from control of viral infections in liver (34), 
lung (35), and brain (36), to regulation of non-infectious diseases like inflammatory bowel disease (37) and cancer (38). Many of these intriguing advances are addressed elsewhere in this Frontiers in Immunology topic, "Interferon- $\lambda s$ : New Regulators of Inflammatory Processes." Here, however, we will focus exclusively on the regulation of enteric viruses by IFN- $\lambda$. We review the current literature about IFN- $\lambda$-mediated regulation of specific intestinal viruses, discuss interplay of IFN- $\lambda$ with other cytokines and its regulation of viral-bacterial interactions, and highlight areas ripe for future research enterprises.

\section{REGULATION OF SPECIFIC ENTERIC VIRUSES BY IFN- $\lambda$}

Enteric viruses, including rotavirus (RV), reovirus, norovirus $(\mathrm{NoV})$, and others, generally infect via the fecal-oral route, though other transmission routes have been described. As such, the IECs comprising the mucosal barrier of the intestine likely represent the first eukaryotic cells with which an enteric virus interacts. Here, we describe what is known about specific enteric viruses and their relationship with both the intestinal epithelium and IFN- $\lambda$ (Table 1).

\section{Rotavirus}

Rotaviruses are double-stranded RNA viruses of the Reoviridae family and a major cause of severe diarrhea in children worldwide (39). RV infection exhibits a preferential tropism for IECs of the small intestinal villi in humans and mice (40). Several groups have reported antiviral effects of IFN- $\lambda$ against RV in mouse models $(16,24,41)$. Infection by a murine RV, EDIM-RV, induces IFN- $\lambda$ in the small intestine, and endogenous IFN- $\lambda$ suppresses intestinal viral replication $(16,41)$. RIG-I and MDA5

TABLE 1 | Interferon-lambda (IFN- $\lambda$ ) interactions with intestinal viruses in vivo and in vitro.

\begin{tabular}{|c|c|c|c|c|}
\hline Virus & Strain & In vivo phenotypes & In vitro phenotypes & Reference \\
\hline \multirow[t]{4}{*}{ Rotavirus (RV) } & EDIM & $\begin{array}{l}\text { * Mice lacking IfnIr } 1 \text { in all cells exhibit increased viral shedding, } \\
\text { intestinal titers, and tissue damage } \\
\text { * RV infection induces IFN- } \lambda \text { production in intestinal epithelial cells (IECs) } \\
\text { * Treatment with exogenous IFN- } \lambda \text { prevents RV replication in the intestine }\end{array}$ & & $(16,41)$ \\
\hline & EW & $\begin{array}{l}\text { * Mice lacking Ifn/r1, Ifnar } 1 \text {, or Stat1 in all cells exhibit similar } \\
\text { level of viral shedding, intestinal titers }\end{array}$ & & (24) \\
\hline & $\begin{array}{l}\text { Rhesus strain } \\
\text { of rotavirus }\end{array}$ & $\begin{array}{l}\text { * Mice lacking Ifn/r1, Ifnar } 1 \text {, or Stat1 in all cells exhibit increased } \\
\text { level of viral shedding, intestinal titers }\end{array}$ & & $(24)$ \\
\hline & Ito, Wa & & $\begin{array}{l}\text { * Human RV infection induces IFN- } \lambda \\
\text { expression in human intestinal enteroids } \\
\text { * Treatment with exogenous IFN- } \lambda \text { inhibits } \\
\text { RV replication in enteroids } \\
\text { * Blocking endogenous IFN- } \lambda \text { has no effect } \\
\text { on viral production }\end{array}$ & $(43)$ \\
\hline
\end{tabular}

\begin{tabular}{|c|c|c|c|c|}
\hline \multirow[t]{2}{*}{ Reovirus } & $\begin{array}{l}\text { Type } 3 \\
\text { Dearing }\end{array}$ & $\begin{array}{l}\text { * Adult mice lacking IfnIr1 in all cells exhibit higher viral } \\
\text { shedding of reovirus } \\
\text { * Suckling mice lacking Ifn/r1 in all cells exhibit higher viral } \\
\text { shedding and tissue titers of reovirus, increased tissue } \\
\text { damage and severe mortality } \\
\text { * Mice lacking Ifnlr1 exhibit higher reovirus infection in IECs, } \\
\text { while mice lacking Ifnar1 exhibit higher infection in lamina propria cells }\end{array}$ & & (14) \\
\hline & Type 1 Lang & $\begin{array}{l}\text { * Mice lacking Ifnlr1 in all cells or only in IECs exhibit higher } \\
\text { viral shedding and intestinal titers of reovirus }\end{array}$ & & (50) \\
\hline \multirow[t]{2}{*}{ Norovirus } & CR6 & $\begin{array}{l}\text { * Mice lacking IfnIr1 in all cells or only in IECs exhibit higher } \\
\text { viral shedding and intestinal titers of persistent murine NoV (MNoV) } \\
\text { * Treatment with recombinant IFN- } \lambda \text { prevents and cures } \\
\text { persistent MNoV infection, dependent on IEC expression of Ifn/r1 } \\
\text { * NoV dependence on the commensal microbiome for } \\
\text { infection is absent in mice lacking Ifn/r1 }\end{array}$ & & $(50,64,93)$ \\
\hline & & & $\begin{array}{l}\text { * Replication of transfected human NoV } \\
\text { RNA is sensitive to IFN- } \lambda \text { treatment, but } \\
\text { does not induce IFN- } \lambda \text { expression }\end{array}$ & (59) \\
\hline Enterovirus & EV71 & & $\begin{array}{l}\text { * Enterovirus } 71 \text { induces IFN- } \lambda \text { expression in } \\
\text { human IEC line }\end{array}$ & (72) \\
\hline Parvovirus & & & $\begin{array}{l}\text { * Canine parvovirus is more sensitive to } \\
\text { IFN- } \lambda \text { than type I IFN }\end{array}$ & (73) \\
\hline Coronavirus & $\begin{array}{l}\text { CV777 } \\
\text { LNCT2 }\end{array}$ & & $\begin{array}{l}\text { * Porcine epidemic diarrhea virus is sensitive } \\
\text { to IFN- } \lambda \text { when cultured in a porcine IEC line }\end{array}$ & $(74)$ \\
\hline
\end{tabular}


are required for type I IFN production by IECs during RV infection (42); induction pathways for IFN- $\lambda$ have not been reported. IECs produce the majority of IFN- $\lambda$, consistent with the viral IEC tropism (16). Pretreatment with exogenous IFN- $\lambda$ effectively prevents EDIM-RV replication in the small intestine and colon (41). However, a recent study demonstrated that a homologous murine strain of RV, EW-RV, is largely IFN- $\lambda$-insensitive, even though EW-RV is originally derived from EDIM-RV (24). This study also showed that a heterologous rhesus strain of rotavirus (RRV) is, in contrast, highly sensitive to both IFN- $\alpha / \beta$ and IFN- $\lambda$, even though EW-RV and RRV infection both significantly induce IFN- $\alpha / \beta$ and IFN- $\lambda$ production during infection (24). The reason for this discrepancy between strains is still unclear, though recently, a human RV study using human intestinal enteroids provided some hints regarding the source of this strain complexity (43). In this study, human RV infection in enteroids indeed induced IFN- $\lambda$ and interferon-stimulated genes (ISGs). However, blocking IFN- $\lambda$ signaling did not have any effect on viral growth. Since RV has multiple functional proteins for immune evasion (e.g., NSP1, NSP3, and VP3) (44), the effect of IFN- $\lambda$ may be limited by these viral genes, and EW-RV may utilize evasion strategies to overcome IFN responses. Thus, interactions between $\mathrm{RV}$ and IFN- $\lambda$ in the intestine are influenced by multiple host and viral factors.

\section{Reovirus}

Although reoviruses are also in the Reoviridae family, in contrast to RVs, they are not generally associated with serious human disease. Recently, however, they have been implicated in the pathogenesis of celiac disease, suggesting the possibility of a previously overlooked role as an environmental inflammatory trigger (45). Importantly, reoviruses have been used as a tractable experimental system for studies of viral pathogenesis in newborn mice (46). Reoviruses induce type I and III IFNs in a MAVS-dependent fashion (13, 15, 47), likely via RIG-I- and MDA5-mediated sensing $(48,49)$. Since these viruses exhibit a wide cellular tropism and a low degree of species specificity, reovirus infection of the mouse intestine is sensitive to both IFN- $\alpha / \beta$ and IFN- $\lambda$ (14). In adult mice, endogenous IFN- $\lambda$ inhibits reovirus strain Type 3 Dearing replication in the intestine, and reovirus replicates exclusively in IECs of Ifnlr1-deficient mice (14). By contrast, IFN- $\alpha / \beta$ inhibits reovirus replication in the intestine, but acts specifically on cells in the lamina propria. Another study using reovirus strain Type 1 Lang showed that endogenous IFN- $\lambda$ inhibits reovirus replication in the mouse small intestine and that IFN- $\lambda$-receptor expression in IECs is critical for this antiviral activity (50). Therefore, IFN $-\lambda$ in the intestine controls reovirus replication in IECs, but IFN- $\alpha / \beta$ also coordinately controls reovirus infection in non-IEC cell types in the intestine.

\section{Norovirus}

Noroviruses are positive sense non-enveloped RNA viruses in the Caliciviridae family (51). In humans, they are the most common cause of epidemic gastroenteritis and are a significant contributor to childhood mortality worldwide $(52,53)$. In addition to causing acute symptomatic infections characterized by vomiting and diarrhea, they can persist in both immunocompetent (54) and immunocompromised individuals (55), who can potentially seed future epidemics (56). Until quite recently, human NoV has been impractical to culture in vitro $(57,58)$ and lacked a robust small animal model. Secondary to these challenges, the role of IFN- $\lambda$ in control of human $\mathrm{NoV}$ in vivo is unknown. In vitro, human NoV RNA replication and virus production, after transfection of stool-isolated RNA into mammalian cells, is sensitive to treatment with type I and III IFNs (59). However, in this system, NoV RNA replication does not induce IFNs or respond to neutralization of type I or III IFNs (59). Whether this reflects the in vivo effects of $\mathrm{NoV}$ infection remains to be seen.

The discovery of murine $\mathrm{NoV}(\mathrm{MNoV})(60)$, which is readily culturable (61) and can be studied in vivo, facilitated exploration of the interactions between $\mathrm{NoV}$ and the host immune system (62). IFNs have long been known to be important in MNoV regulation, as the virus was originally isolated from and causes severe disease and death in Stat1-deficient mice $(60,63)$. Type I and II IFNs both control acute, systemically spreading strains of $\mathrm{MNoV}$ [recently reviewed in Ref. (62)]. By contrast, type I and II IFNs are dispensable for intestinal regulation of persistent strains of MNoV (64), which replicate robustly in the colon and are shed at high levels in the stool (65). Instead, for persistent MNoV, IFN- $\lambda$ plays a critical regulatory role. Endogenous IFN- $\lambda$ controls intestinal viral replication and shedding, demonstrated by increased shedding in Ifnlr1-deficient mice. In addition, exogenous IFN- $\lambda$ prevents and cures persistent $\mathrm{MNoV}$ infection in wild-type and Rag1-deficient mice (64). Thus, IFN- $\lambda$ represents an example of sterilizing innate immunity. Because myeloid and B cells, which support $\mathrm{MNoV}$ replication in vitro $(57,61)$, and IECs, the target cells of IFN- $\lambda$ for $\mathrm{MNoV}$ clearance (50), are distinct, it remains to be determined whether in vivo IFN- $\lambda$ stimulates an antiviral program in a cell-intrinsic fashion to clear infected IECs, or instead drives production of secondary factors to target infected myeloid or B cells.

Induction of IFN- $\lambda$ is also important for control of intestinal MNoV. MDA5 is critical for type I IFN responses to MNoV (66); type III IFN responses may be similarly regulated. Nod-like receptor Nlrp6 is another viral RNA sensor that regulates intestinal MNoV levels and plays a role in induction of type I and III IFNs and ISGs in response to infection (67). Activated intestinal intraepithelial lymphocytes have been shown to rapidly stimulate type I and III IFN receptor-dependent upregulation of ISGs in IECs, which correspondingly limits MNoV infection in vivo (68). Persistent strains of MNoV may induce lower levels of type I and III IFNs than acute systemic strains, such that avoidance of IFN upregulation may contribute to persistence of some strains (64).

Identifying viral antagonists of host pathways can highlight critical antiviral host pathways. MNoV antagonizes IFNs via a protein expressed from ORF4, VF1, which in vitro delays upregulation of innate genes including type I IFNs (69). MNoV has also been shown to diminish the host response to infection via its protease NS6, which specifically suppresses host ISG translation (70). However, the interactions of these genes with IFN- $\lambda$ signaling in the intestine have not yet been explored. A final potential viral player of interest is $\mathrm{MNoV}$ NS1/2. A single amino acid difference in this gene confers the ability of the virus to persist in the intestine and stool (65). It is a tempting speculation 
that intestinal viral persistence requires antagonism of IFN- $\lambda$, but further studies are needed to determine whether NoV has evolved to avoid the antiviral effects of this signaling pathway.

\section{Other Enteric Viruses}

A limited number of studies have explored the role of IFN- $\lambda$ in regulation of other enteric viruses. Infection of human enteroids by echovirus 11 , but not coxsackievirus $B$, was shown to induce expression of antiviral ISGs (71), and enterovirus 71 potently induces type I and III IFNs in a human IEC line (72). However, further studies are needed to determine the specific role of type III IFNs in control of enteroviruses. Canine parvovirus, which causes gastrointestinal disease in dogs, is more sensitive to IFN- $\lambda$ than a type I IFN in vitro (73), but it is unknown whether this applies to human parvoviruses. Porcine epidemic diarrhea virus is an enteropathogenic coronavirus that is sensitive to both type I and III IFN treatment in a porcine IEC line (74). Finally, avian influenza virus and Newcastle disease virus induce much more robust type III than type I IFN in a primary chicken IEC culture model, suggesting a possible role for IFN- $\lambda$ in prevention of intestinal infection by these viruses normally associated with respiratory infections (75). These initial findings point to the potential for a broad role for IFN- $\lambda$ in control of many different enteric viruses, but additional studies are clearly needed to determine the breadth and depth of IFN- $\lambda$-mediated regulation of viral infection in the intestine.

\section{IFN- $\lambda$ INTERACTIONS WITH OTHER SIGNALING PATHWAYS}

Interferon-lambda-mediated antiviral immunity in the intestine against rotavirus (EDIM-RV) and $\mathrm{MNoV}$ does not redundantly overlap with type I IFNs, while there is redundancy between type I and III IFNs to control influenza, SARS coronavirus, and respiratory syncytial virus in the lung, and herpes simplex virus- 2 in the genital tract [reviewed in Ref. (76)]. There are two potential reasons for a non-redundant role for IFN- $\lambda$ in the intestine. First, the IFN- $\lambda$ receptor is highly expressed in IECs but is minimally detectable in other intestinal cell types such as lamina propria cells (50). Second, expression of IFN- $\alpha$ receptor subunits (i.e., IFNAR1 and IFNAR2) is less abundant in IECs than in lamina propria cells (14), and surface expression of the IFN- $\alpha$ receptor is polarized to the apical side (41). Interestingly, in neonatal mice, IECs are sensitive to both IFN- $\alpha / \beta$ and IFN- $\lambda$, and both IFN- $\alpha / \beta$ and IFN- $\lambda$ can control RV (RRV strain) infection in suckling mice (24). It has not been explored whether this IFN- $\alpha / \beta$-sensitivity in neonatal IECs is from altered trafficking of the IFN- $\alpha$ receptor to the basolateral side. Further work is needed to explore the consequences of age-related IFN- $\alpha / \beta$ sensitivity in IECs and the pathogenesis of enteric virus infection (Figure 1).

Another cytokine important for mucosal immunity, IL-22, has a synergistic relationship with IFN- $\lambda$. Similar to IFNLR1, the IL-22 receptor subunit, IL22R $\alpha$, associates with IL10R $\beta$ and is expressed preferentially by IECs (77). During RV infection, IL-22 acts coordinately with IFN- $\lambda$ to control virus replication and prevent tissue damage in mice (16). This antiviral activity of IL-22 is Ifnlr1 and Stat1 dependent but not Stat3 dependent.
IL-22 also restricts porcine enteric coronavirus infection in the intestine, for which antiviral activity is largely Stat3 dependent (78). Since IL-22 also induces IFN- $\lambda$ expression in the intestine, a Stat3-independent/IFN- $\lambda$-dependent role for IL-22 in control of porcine enteric coronavirus cannot be ruled out (78).

Finally, lactoferrin, a member of the transferrin family and a component of milk, potentiates IFN- $\lambda$ production in a human IEC line (79), and in vitro lactoferrin has antiviral activity against RV (80) and MNoV (81). Thus, it would be interesting to study whether milk-derived components exhibit cross talk with IFN- $\lambda$ mediated immunity for enteric viral infections in neonatal hosts.

\section{IFN- $\lambda$ AND TRANSKINGDOM INTERACTIONS}

A final critical factor for discussion of enteric viral infections and IFN- $\lambda$ is the role of the commensal bacterial microbiome. For these viruses, infection occurs amidst the complex milieu of the oral and intestinal microbiome, which plays important roles in regulation of viral infectivity. Poliovirus, reovirus, and murine mammary tumor virus depend upon the presence of commensal bacteria for infection $(82,83)$, with direct viral binding to bacterial products like lipopolysacchide implicated as the mechanism of facilitation $(84,85)$. Depletion of the commensal microbiota also impairs RV infection and results in enhancement of both mucosal and systemic antibody responses against the virus (86). Human NoV binds directly to bacterial products that mimic the histo-blood group antigens (HBGAs) known to be attachment factors for NoV (87-89), and indeed culture of human NoV in $\mathrm{B}$ cells depends on the presence of these HBGA-expressing bacteria $(57,90)$. Hence, there is a common theme for enteric viruses in interacting with and depending on intestinal bacteria for infectivity, though the specific mechanisms may be virus dependent $(91,92)$.

The link between viral dependence on the microbiome and sensitivity to IFN- $\lambda$ comes from work done with MNoV. Depletion of the commensal microbiota in wild-type mice prevents persistent intestinal $\mathrm{MNoV}$ infection (93), similar to what has been observed with other enteric viruses. Interestingly, in mice lacking Ifnlr1, Stat1, or Irf3, all important molecules for IFN- $\lambda$ induction or signaling, MNoV establishes infection even in the absence of commensal microbes, implicating IFN- $\lambda$ in regulation of these transkingdom viral-bacterial interactions (93) (Figure 1). Other enteric viruses share both a dependence on the microbiome and a sensitivity to IFN- $\lambda$; whether interplay between the microbiome and IFN- $\lambda$ signaling also regulates other intestinal viruses such as RV and reovirus remains to be seen.

\section{GUT INSTINCT ABOUT THE FUTURE OF IFN- $\lambda$}

While the past decade yielded many exciting insights into regulation of enteric viruses by IFN- $\lambda$, many important questions remain. Type I and III IFNs share significant overlap in induction and signaling pathways, though there are distinctions in promoter sequences, upstream regulatory elements, and kinetics of downstream gene stimulation [reviewed in Ref. (76)]. However, most 
previous studies were performed in vitro outside of the complex environment of the gut. How is IFN- $\lambda$ production regulated in the intestine, and by what pathways is it induced in vivo by viral infection? Are specific ISGs induced by IFN- $\lambda$ necessary for antiviral activity against enteric infections? Conversely, viruses rapidly evolve mechanisms to evade the host immune system. Are there viral factors that specifically target IFN $-\lambda$ induction or signaling pathways for evasion or suppression?

In addition to important mechanistic questions for enteric viruses already known to be IFN- $\lambda$ regulated, there are a number of intestinal viruses for which sensitivity to IFN- $\lambda$ has not yet been explored. Astroviruses, parvoviruses, enteroviruses, and adenoviruses are among the enteric viruses for which data on IFN- $\lambda$-sensitivity in both cell culture and animal models is currently lacking. Finally, of great interest is the in vivo effect of IFN- $\lambda$ regulation on enteric viruses in humans. Single-nucleotide polymorphisms (SNPs) in human IFN- $\lambda$ genes are associated with differential responses to hepatitis $\mathrm{B}$ and $\mathrm{C}$, human cytomegalovirus, herpes simplex virus 1 , and influenza virus vaccination [reviewed in Ref. $(76,94)$ ]. Enteric infections cause a spectrum

\section{REFERENCES}

1. Wang BX, Fish EN. The yin and yang of viruses and interferons. Trends Immunol (2012) 33(4):190-7. doi:10.1016/j.it.2012.01.004

2. Sheppard P, Kindsvogel W, Xu W, Henderson K, Schlutsmeyer S, Whitmore TE, et al. IL-28, IL-29 and their class II cytokine receptor IL-28R. Nat Immunol (2003) 4(1):63-8. doi:10.1038/ni873

3. Kotenko SV, Gallagher G, Baurin VV, Lewis-Antes A, Shen M, Shah NK, et al. IFN-lambdas mediate antiviral protection through a distinct class II cytokine receptor complex. Nat Immunol (2003) 4(1):69-77. doi:10.1038/ni875

4. Prokunina-Olsson L, Muchmore B, Tang W, Pfeiffer RM, Park H, Dickensheets H, et al. A variant upstream of IFNL3 (IL28B) creating a new interferon gene IFNL4 is associated with impaired clearance of hepatitis C virus. Nat Genet (2013) 45(2):164-71. doi:10.1038/ng.2521

5. Hong M, Schwerk J, Lim C, Kell A, Jarret A, Pangallo J, et al. Interferon lambda 4 expression is suppressed by the host during viral infection. J Exp Med (2016) 213(12):2539-52. doi:10.1084/jem.20160437

6. Bartlett NW, Buttigieg K, Kotenko SV, Smith GL. Murine interferon lambdas (type III interferons) exhibit potent antiviral activity in vivo in a poxvirus infection model. J Gen Virol (2005) 86(Pt 6):1589-96. doi:10.1099/ vir.0.80904-0

7. Lasfar A, Lewis-Antes A, Smirnov SV, Anantha S, Abushahba W, Tian B, et al. Characterization of the mouse IFN-lambda ligand-receptor system: IFNlambdas exhibit antitumor activity against B16 melanoma. Cancer Res (2006) 66(8):4468-77. doi:10.1158/0008-5472.CAN-05-3653

8. Zou J, Tafalla C, Truckle J, Secombes CJ. Identification of a second group of type I IFNs in fish sheds light on IFN evolution in vertebrates. JImmunol (2007) 179(6):3859-71. doi:10.4049/jimmunol.179.6.3859

9. Fox BA, Sheppard PO, O'Hara PJ. The role of genomic data in the discovery, annotation and evolutionary interpretation of the interferon-lambda family. PLoS One (2009) 4(3):e4933. doi:10.1371/journal.pone.0004933

10. Ank N, West H, Bartholdy C, Eriksson K, Thomsen AR, Paludan SR. Lambda interferon (IFN-lambda), a type III IFN, is induced by viruses and IFNs and displays potent antiviral activity against select virus infections in vivo. J Virol (2006) 80(9):4501-9. doi:10.1128/JVI.80.9.4501-4509.2006

11. Onoguchi K, Yoneyama M, Takemura A, Akira S, Taniguchi T, Namiki H, et al. Viral infections activate types I and III interferon genes through a common mechanism. J Biol Chem (2007) 282(10):7576-81. doi:10.1074/jbc.M608618200

12. Osterlund PI, Pietila TE, Veckman V, Kotenko SV, Julkunen I. IFN regulatory factor family members differentially regulate the expression of type III IFN (IFN-lambda) genes. JImmunol (2007) 179(6):3434-42. doi:10.4049/ jimmunol.179.6.3434 of disease in different individuals, including variable severity and duration of infection, which may correlate with host genetic variation. Do these same SNPs correlate with differential responses to enteric viruses or to vaccination? IFN- $\lambda$ is clearly an important innate immune regulator for many gut viruses, and defining the breadth of its effects and the mechanisms underlying its enteric activity represent exciting areas for future research endeavors.

\section{AUTHOR CONTRIBUTIONS}

All authors contributed equally to this work. SL and MB conceptualized, wrote, and edited the manuscript.

\section{FUNDING}

SL was supported by the Basic Science Research Program through the National Research Foundation of Korea funded by the Ministry of Education (NRF-2016R1A6A3A03012352). MB was supported by National Institutes of Health (NIH) grant K22 AI127846-01 and by DDRCC grant P30 DK052574.

13. Odendall C, Dixit E, Stavru F, Bierne H, Franz KM, Durbin AF, et al. Diverse intracellular pathogens activate type III interferon expression from peroxisomes. Nat Immunol (2014) 15(8):717-26. doi:10.1038/ni.2915

14. Mahlakoiv T, Hernandez P, Gronke K, Diefenbach A, Staeheli P. Leukocytederived IFN-alpha/beta and epithelial IFN-lambda constitute a compartmentalized mucosal defense system that restricts enteric virus infections. PLoS Pathog (2015) 11(4):e1004782. doi:10.1371/journal.ppat.1004782

15. Pervolaraki K, Stanifer ML, Munchau S, Renn LA, Albrecht D, Kurzhals S, et al. Type I and type III interferons display different dependency on mitogen-activated protein kinases to mount an antiviral state in the human gut. Front Immunol (2017) 8:459. doi:10.3389/fimmu.2017.00459

16. Hernandez PP, Mahlakoiv T, Yang I, Schwierzeck V, Nguyen N, Guendel F, et al. Interferon-lambda and interleukin 22 act synergistically for the induction of interferon-stimulated genes and control of rotavirus infection. Nat Immunol (2015) 16(7):698-707. doi:10.1038/ni.3180

17. Hillyer P, Mane VP, Schramm LM, Puig M, Verthelyi D, Chen A, et al. Expression profiles of human interferon-alpha and interferon-lambda subtypes are ligand- and cell-dependent. Immunol Cell Biol (2012) 90(8):774-83. doi:10.1038/icb.2011.109

18. He SH, Song CH, Liu Z, Zhang H, Ma W, Zhou LF, et al. Eosinophil-derived interferon-lambda contributes to initiation of allergen-related inflammation in the intestine. Cytokine (2012) 58(2):186-92. doi:10.1016/j.cyto.2012.01.003

19. Raki M, Beitnes AC, Lundin KE, Jahnsen J, Jahnsen FL, Sollid LM. Plasmacytoid dendritic cells are scarcely represented in the human gut mucosa and are not recruited to the celiac lesion. Mucosal Immunol (2013) 6(5):985-92. doi:10.1038/mi.2012.136

20. Zhou Z, Hamming OJ, Ank N, Paludan SR, Nielsen AL, Hartmann R. Type III interferon (IFN) induces a type I IFN-like response in a restricted subset of cells through signaling pathways involving both the Jak-STAT pathway and the mitogen-activated protein kinases. J Virol (2007) 81(14):7749-58. doi:10.1128/ JVI.02438-06

21. Marcello T, Grakoui A, Barba-Spaeth G, Machlin ES, Kotenko SV, MacDonald MR, et al. Interferons alpha and lambda inhibit hepatitis $\mathrm{C}$ virus replication with distinct signal transduction and gene regulation kinetics. Gastroenterology (2006) 131(6):1887-98. doi:10.1053/j.gastro.2006.09.052

22. Voigt EA, Yin J. Kinetic differences and synergistic antiviral effects between type I and type III interferon signaling indicate pathway independence. J Interferon Cytokine Res (2015) 35(9):734-47. doi:10.1089/jir.2015.0008

23. Sommereyns C, Paul S, Staeheli P, Michiels T. IFN-lambda (IFN-lambda) is expressed in a tissue-dependent fashion and primarily acts on epithelial cells in vivo. PLoS Pathog (2008) 4(3):e1000017. doi:10.1371/journal.ppat. 1000017 
24. Lin JD, Feng N, Sen A, Balan M, Tseng HC, McElrath C, et al. Distinct roles of type I and type III interferons in intestinal immunity to homologous and heterologous rotavirus infections. PLoS Pathog (2016) 12(4):e1005600. doi:10.1371/journal.ppat.1005600

25. Pulverer JE, Rand U, Lienenklaus S, Kugel D, Zietara N, Kochs G, et al. Temporal and spatial resolution of type I and III interferon responses in vivo. J Virol (2010) 84(17):8626-38. doi:10.1128/JVI.00303-10

26. Souza-Fonseca-Guimaraes F, Young A, Mittal D, Martinet L, Bruedigam C, Takeda K, et al. NK cells require IL-28R for optimal in vivo activity. Proc Natl Acad Sci U S A (2015) 112(18):E2376-84. doi:10.1073/pnas.1424241112

27. He SH, Chen X, Song CH, Liu ZQ, Zhou LF, Ma WJ, et al. Interferon-lambda mediates oral tolerance and inhibits antigen-specific, T-helper 2 cell-mediated inflammation in mouse intestine. Gastroenterology (2011) 141(1):249-58, 258. e1-2. doi:10.1053/j.gastro.2011.04.006

28. Witte K, Gruetz G, Volk HD, Looman AC, Asadullah K, Sterry W, et al. Despite IFN-lambda receptor expression, blood immune cells, but not keratinocytes or melanocytes, have an impaired response to type III interferons: implications for therapeutic applications of these cytokines. Genes Immun (2009) 10(8):702-14. doi:10.1038/gene.2009.72

29. Kelly A, Robinson MW, Roche G, Biron CA, O'Farrelly C, Ryan EJ. Immune cell profiling of IFN-lambda response shows pDCs express highest level of IFN-lambdaR1 and are directly responsive via the JAK-STAT pathway. J Interferon Cytokine Res (2016) 36(12):671-80. doi:10.1089/jir.2015.0169

30. de Groen RA, Groothuismink ZM, Liu BS, Boonstra A. IFN-lambda is able to augment TLR-mediated activation and subsequent function of primary human B cells. J Leukoc Biol (2015) 98(4):623-30. doi:10.1189/jlb.3A0215-041RR

31. Pott J, Stockinger S. Type I and III interferon in the gut: tight balance between host protection and immunopathology. Front Immunol (2017) 8:258. doi:10.3389/fimmu.2017.00258

32. Crow YJ. Type I interferonopathies: a novel set of inborn errors of immunity. Ann N Y Acad Sci (2011) 1238:91-8. doi:10.1111/j.1749-6632.2011.06220.x

33. Chen K, Liu J, Cao X. Regulation of type I interferon signaling in immunity and inflammation: a comprehensive review. JAutoimmun (2017). doi:10.1016/j.jaut.2017.03.008

34. Boisvert M, Shoukry NH. Type III interferons in hepatitis C virus infection. Front Immunol (2016) 7:628. doi:10.3389/fimmu.2016.00628

35. Davidson S, McCabe TM, Crotta S, Gad HH, Hessel EM, Beinke S, et al. IFNlambda is a potent anti-influenza therapeutic without the inflammatory side effects of IFNalpha treatment. EMBO Mol Med (2016) 8(9):1099-112. doi:10.15252/emmm.201606413

36. Lazear HM, Daniels BP, Pinto AK, Huang AC, Vick SC, Doyle SE, et al. Interferon-lambda restricts West Nile virus neuroinvasion by tightening the blood-brain barrier. Sci Transl Med (2015) 7(284):284ra59. doi:10.1126/ scitranslmed.aaa4304

37. Chiriac MT, Buchen B, Wandersee A, Hundorfean G, Gunther C, Bourjau Y, et al. Activation of epithelial signal transducer and activator of transcription 1 by interleukin 28 controls mucosal healing in mice with colitis and is increased in mucosa of patients with inflammatory bowel disease. Gastroenterology (2017). doi:10.1053/j.gastro.2017.03.015

38. Lasfar A, Gogas H, Zloza A, Kaufman HL, Kirkwood JM. IFN-lambda cancer immunotherapy: new kid on the block. Immunotherapy (2016) 8(8):877-88. doi:10.2217/imt-2015-0021

39. Tate JE, Burton AH, Boschi-Pinto C, Steele AD, Duque J, Parashar UD, et al. Network: 2008 estimate of worldwide rotavirus-associated mortality in children younger than 5 years before the introduction of universal rotavirus vaccination programmes: a systematic review and meta-analysis. Lancet Infect Dis (2012) 12(2):136-41. doi:10.1016/S1473-3099(11)70253-5

40. Lopez S, Arias CF. Early steps in rotavirus cell entry. Curr Top Microbiol Immunol (2006) 309:39-66. doi:10.1007/3-540-30773-7_2

41. Pott J, Mahlakoiv T, Mordstein M, Duerr CU, Michiels T, Stockinger S, et al. IFN-lambda determines the intestinal epithelial antiviral host defense. Proc Natl Acad Sci U S A (2011) 108(19):7944-9. doi:10.1073/pnas.1100552108

42. Broquet AH, Hirata Y, McAllister CS, Kagnoff MF. RIG-I/MDA5/MAVS are required to signal a protective IFN response in rotavirus-infected intestinal epithelium. J Immunol (2011) 186(3):1618-26. doi:10.4049/jimmunol.1002862

43. Saxena K, Simon LM, Zeng XL, Blutt SE, Crawford SE, Sastri NP, et al. A paradox of transcriptional and functional innate interferon responses of human intestinal enteroids to enteric virus infection. Proc Natl Acad Sci U S A (2017) 114(4):E570-9. doi:10.1073/pnas.1615422114
44. Arnold MM, Sen A, Greenberg HB, Patton JT. The battle between rotavirus and its host for control of the interferon signaling pathway. PLoS Pathog (2013) 9(1):e1003064. doi:10.1371/journal.ppat.1003064

45. Bouziat R, Hinterleitner R, Brown JJ, Stencel-Baerenwald JE, Ikizler M, Mayassi T, et al. Reovirus infection triggers inflammatory responses to dietary antigens and development of celiac disease. Science (2017) 356(6333):44-50. doi:10.1126/science.aah5298

46. Forrest JC, Dermody TS. Reovirus receptors and pathogenesis. J Virol (2003) 77(17):9109-15. doi:10.1128/JVI.77.17.9109-9115.2003

47. Bender S, Reuter A, Eberle F, Einhorn E, Binder M, Bartenschlager R. Activation of type I and III interferon response by mitochondrial and peroxisomal MAVS and inhibition by hepatitis C virus. PLoS Pathog (2015) 11(11):e1005264. doi:10.1371/journal.ppat.1005264

48. Goubau D, Schlee M, Deddouche S, Pruijssers AJ, Zillinger T, Goldeck M, et al. Antiviral immunity via RIG-I-mediated recognition of RNA bearing 5'-diphosphates. Nature (2014) 514(7522):372-5. doi:10.1038/nature13590

49. Loo YM, Fornek J, Crochet N, Bajwa G, Perwitasari O, Martinez-Sobrido L, et al. Distinct RIG-I and MDA5 signaling by RNA viruses in innate immunity. J Virol (2008) 82(1):335-45. doi:10.1128/JVI.01080-07

50. Baldridge MT, Lee S, Brown JJ, McAllister N, Urbanek K, Dermody TS, et al. Expression of Ifnlr 1 on intestinal epithelial cells is critical to the antiviral effects of IFN-lambda against norovirus and reovirus. J Virol (2017) 91:e2079-2016. doi:10.1128/JVI.02079-16

51. Karst SM, Wobus CE, Goodfellow IG, Green KY, Virgin HW. Advances in norovirus biology. Cell Host Microbe (2014) 15(6):668-80. doi:10.1016/j. chom.2014.05.015

52. Bartsch SM, Lopman BA, Ozawa S, Hall AJ, Lee BY. Global economic burden of norovirus gastroenteritis. PLoS One (2016) 11(4):e0151219. doi:10.1371/ journal.pone.0151219

53. Lopman BA, Hall AJ, Curns AT, Parashar UD. Increasing rates of gastroenteritis hospital discharges in US adults and the contribution of norovirus, 1996-2007. Clin Infect Dis (2011) 52(4):466-74. doi:10.1093/cid/ciq163

54. Saito M, Goel-Apaza S, Espetia S, Velasquez D, Cabrera L, Loli S, et al. Multiple norovirus infections in a birth cohort in a Peruvian Periurban community. Clin Infect Dis (2014) 58(4):483-91. doi:10.1093/cid/cit763

55. Siebenga JJ, Beersma MF, Vennema $H$, van Biezen P, Hartwig NJ, Koopmans M. High prevalence of prolonged norovirus shedding and illness among hospitalized patients: a model for in vivo molecular evolution. J Infect Dis (2008) 198(7):994-1001. doi:10.1086/591627

56. Green KY. Norovirus infection in immunocompromised hosts. Clin Microbiol Infect (2014) 20(8):717-23. doi:10.1111/1469-0691.12761

57. Jones MK, Watanabe M, Zhu S, Graves CL, Keyes LR, Grau KR, et al. Enteric bacteria promote human and mouse norovirus infection of B cells. Science (2014) 346(6210):755-9. doi:10.1126/science.1257147

58. Ettayebi K, Crawford SE, Murakami K, Broughman JR, Karandikar UC, Tenge VR, et al. Replication of human noroviruses in stem cell-derived human enteroids. Science (2016) 353(6306):1387-93. doi:10.1126/science.aaf5211

59. Qu L, Murakami K, Broughman JR, Lay MK, Guix S, Tenge VR, et al. Replication of human norovirus RNA in mammalian cells reveals lack of interferon response. J Virol (2016) 90(19):8906-23. doi:10.1128/ JVI.01425-16

60. Karst SM, Wobus CE, Lay M, Davidson J, Virgin HW IV. STAT1-dependent innate immunity to a Norwalk-like virus. Science (2003) 299(5612):1575-8. doi:10.1126/science.1077905

61. Wobus CE, Karst SM, Thackray LB, Chang KO, Sosnovtsev SV, Belliot G, et al. Replication of norovirus in cell culture reveals a tropism for dendritic cells and macrophages. PLoS Biol (2004) 2(12):e432. doi:10.1371/journal. pbio.0020432

62. Baldridge MT, Turula H, Wobus CE. Norovirus regulation by host and microbe. Trends Mol Med (2016) 22(12):1047-59. doi:10.1016/j.molmed.2016.10.003

63. Mumphrey SM, Changotra H, Moore TN, Heimann-Nichols ER, Wobus CE, Reilly MJ, et al. Murine norovirus 1 infection is associated with histopathological changes in immunocompetent hosts, but clinical disease is prevented by STAT1-dependent interferon responses. J Virol (2007) 81(7):3251-63. doi:10.1128/JVI.02096-06

64. Nice TJ, Baldridge MT, McCune BT, Norman JM, Lazear HM, Artyomov M, et al. Interferon-lambda cures persistent murine norovirus infection in the absence of adaptive immunity. Science (2015) 347(6219):269-73. doi:10.1126/ science. 1258100 
65. Nice TJ, Strong DW, McCune BT, Pohl CS, Virgin HW. A single-amino-acid change in murine norovirus NS1/2 is sufficient for colonic tropism and persistence. J Virol (2013) 87(1):327-34. doi:10.1128/JVI.01864-12

66. McCartney SA, Thackray LB, Gitlin L, Gilfillan S, Virgin HW, Colonna M. MDA-5 recognition of a murine norovirus. PLoS Pathog (2008) 4(7):e1000108. doi:10.1371/journal.ppat.1000108

67. Wang P, Zhu S, Yang L, Cui S, Pan W, Jackson R, et al. Nlrp6 regulates intestinal antiviral innate immunity. Science (2015) 350(6262):826-30. doi:10.1126/ science.aab3145

68. Swamy M, Abeler-Dorner L, Chettle J, Mahlakoiv T, Goubau D, Chakravarty P, et al. Intestinal intraepithelial lymphocyte activation promotes innate antiviral resistance. Nat Commun (2015) 6:7090. doi:10.1038/ncomms8090

69. McFadden N, Bailey D, Carrara G, Benson A, Chaudhry Y, Shortland A, et al. Norovirus regulation of the innate immune response and apoptosis occurs via the product of the alternative open reading frame 4. PLoS Pathog (2011) 7(12):e1002413. doi:10.1371/journal.ppat.1002413

70. Emmott E, Sorgeloos F, Caddy SL, Vashist S, Sosnovtsev S, Lloyd R, et al. Norovirus-mediated modification of the translational landscape via virus and host-induced cleavage of translation initiation factors. Mol Cell Proteomics (2017) 16(4 Suppl 1):S215-29. doi:10.1074/mcp.M116.062448

71. Drummond CG, Bolock AM, Ma C, Luke CJ, Good M, Coyne CB. Enteroviruses infect human enteroids and induce antiviral signaling in a cell lineage-specific manner. Proc Natl Acad Sci U S A (2017) 114(7):1672-7. doi:10.1073/pnas.1617363114

72. Wang C, Ji L, Yuan X, Jin Y, Cardona CJ, Xing Z. Differential regulation of TLR signaling on the induction of antiviral interferons in human intestinal epithelial cells infected with enterovirus 71. PLoS One (2016) 11(3):e0152177. doi:10.1371/journal.pone.0152177

73. Fan W, Xu L, Ren L, Qu H, Li J, Liang J, et al. Functional characterization of canine interferon-lambda. J Interferon Cytokine Res (2014) 34(11):848-57. doi:10.1089/jir.2014.0009

74. Li L, Fu F, Xue M, Chen W, Liu J, Shi H, et al. IFN-lambda preferably inhibits PEDV infection of porcine intestinal epithelial cells compared with IFN-alpha. Antiviral Res (2017) 140:76-82. doi:10.1016/j.antiviral.2017.01.012

75. Kaiser A, Willer T, Sid H, Petersen H, Baumgartner W, Steinberg P, et al. Susceptibility of primary chicken intestinal epithelial cells for low pathogenic avian influenza virus and velogenic viscerotropic Newcastle disease virus. Virus Res (2016) 225:50-63. doi:10.1016/j.virusres.2016.09.001

76. Lazear HM, Nice TJ, Diamond MS. Interferon-lambda: immune functions at barrier surfaces and beyond. Immunity (2015) 43(1):15-28. doi:10.1016/j. immuni.2015.07.001

77. Wolk K, Kunz S, Witte E, Friedrich M, Asadullah K, Sabat R. IL-22 increases the innate immunity of tissues. Immunity (2004) 21(2):241-54. doi:10.1016/j. immuni.2004.07.007

78. Xue M, Zhao J, Ying L, Fu F, Li L, Ma Y, et al. IL-22 suppresses the infection of porcine enteric coronaviruses and rotavirus by activating STAT3 signal pathway. Antiviral Res (2017) 142:68-75. doi:10.1016/j.antiviral.2017. 03.006

79. Shin K, Oda H, Wakabayashi H, Yamauchi K, Abe F. Effects of lactoferrin on the production of interferon-lambda by the human intestinal epithelial cell line HT-29. Biochem Cell Biol (2017) 95(1):53-6. doi:10.1139/bcb-2016-0031

80. Superti F, Ammendolia MG, Valenti P, Seganti L. Antirotaviral activity of milk proteins: lactoferrin prevents rotavirus infection in the enterocyte-like cell line HT-29. Med Microbiol Immunol (1997) 186(2-3):83-91. doi:10.1007/ s004300050049

81. Ishikawa H, Awano N, Fukui T, Sasaki H, Kyuwa S. The protective effects of lactoferrin against murine norovirus infection through inhibition of both viral attachment and replication. Biochem Biophys Res Commun (2013) 434(4):791-6. doi:10.1016/j.bbrc.2013.04.013
82. Kuss SK, Best GT, Etheredge CA, Pruijssers AJ, Frierson JM, Hooper LV, et al. Intestinal microbiota promote enteric virus replication and systemic pathogenesis. Science (2011) 334(6053):249-52. doi:10.1126/science. 1211057

83. Kane M, Case LK, Kopaskie K, Kozlova A, MacDearmid C, Chervonsky AV, et al. Successful transmission of a retrovirus depends on the commensal microbiota. Science (2011) 334(6053):245-9. doi:10.1126/science.1210718

84. Wilks J, Lien E, Jacobson AN, Fischbach MA, Qureshi N,Chervonsky AV, et al. Mammalian lipopolysaccharide receptors incorporated into the retroviral envelope augment virus transmission. Cell Host Microbe (2015) 18(4):456-62. doi:10.1016/j.chom.2015.09.005

85. Robinson CM, Jesudhasan PR, Pfeiffer JK. Bacterial lipopolysaccharide binding enhances virion stability and promotes environmental fitness of an enteric virus. Cell Host Microbe (2014) 15(1):36-46. doi:10.1016/j.chom.2013. 12.004

86. Uchiyama R, Chassaing B, Zhang B, Gewirtz AT. Antibiotic treatment suppresses rotavirus infection and enhances specific humoral immunity. J Infect Dis (2014) 210(2):171-82. doi:10.1093/infdis/jiu037

87. Miura T, Sano D, Suenaga A, Yoshimura T, Fuzawa M, Nakagomi T, et al. Histo-blood group antigen-like substances of human enteric bacteria as specific adsorbents for human noroviruses. J Virol (2013) 87(17):9441-51. doi:10.1128/JVI.01060-13

88. Amarasiri M, Hashiba S, Miura T, Nakagomi T, Nakagomi O, Ishii S, et al. Bacterial histo-blood group antigens contributing to genotype-dependent removal of human noroviruses with a microfiltration membrane. Water Res (2016) 95:383-91. doi:10.1016/j.watres.2016.04.018

89. Almand EA, Moore MD, Outlaw J, Jaykus LA. Human norovirus binding to select bacteria representative of the human gut microbiota. PLoS One (2017) 12(3):e0173124. doi:10.1371/journal.pone.0173124

90. Jones MK, Grau KR, Costantini V, Kolawole AO, de Graaf M, Freiden P, et al. Human norovirus culture in B cells. Nat Protoc (2015) 10(12):1939-47. doi:10.1038/nprot.2015.121

91. Pfeiffer JK, Virgin HW. Viral immunity. Transkingdom control of viral infection and immunity in the mammalian intestine. Science (2016) 351(6270):239. doi:10.1126/science.aad5872

92. Karst SM. The influence of commensal bacteria on infection with enteric viruses. Nat Rev Microbiol (2016) 14(4):197-204. doi:10.1038/nrmicro.2015.25

93. Baldridge MT, Nice TJ, McCune BT, Yokoyama CC, Kambal A, Wheadon $\mathrm{M}$, et al. Commensal microbes and interferon-lambda determine persistence of enteric murine norovirus infection. Science (2015) 347(6219):266-9. doi:10.1126/science.1258025

94. Griffiths SJ, Dunnigan CM, Russell CD, Haas JG. The role of interferon-lambda locus polymorphisms in hepatitis $\mathrm{C}$ and other infectious diseases. J Innate Immun (2015) 7(3):231-42. doi:10.1159/000369902

Conflict of Interest Statement: The authors declare that the research was conducted in the absence of any commercial or financial relationships that could be construed as a potential conflict of interest.

The reviewer, YT, and handling editor declared their shared affiliation, and the handling editor states that the process nevertheless met the standards of a fair and objective review.

Copyright $\odot 2017$ Lee and Baldridge. This is an open-access article distributed under the terms of the Creative Commons Attribution License (CC BY). The use, distribution or reproduction in other forums is permitted, provided the original author(s) or licensor are credited and that the original publication in this journal is cited, in accordance with accepted academic practice. No use, distribution or reproduction is permitted which does not comply with these terms. 